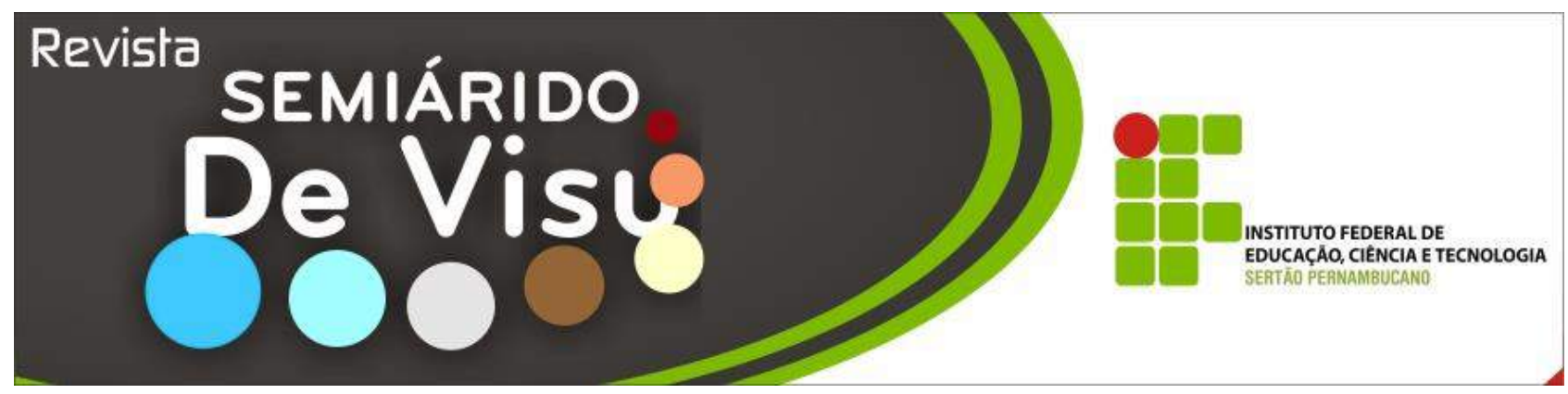

\title{
Concepções de leitura no Exame Nacional do Ensino Médio: uma análise das provas de língua espanhola
}

\author{
Maria Rafaela Vieira da Silva ${ }^{1}, K_{e}$ lvya Freitas Abreu² \\ 1,2, Instituto Federal de Educação, Ciência e Tecnologia do Sertão Pernambucano - Campus Salgueiro. BR 232, Km 508 sentido \\ Recife, Zona Rural. CEP: 56000-000 | Salgueiro/PE - Brasil | Telefone: (87) 34210050 |E-mail: ${ }^{1}$ rafaelaifte@ hotmail.com; ${ }^{2}$ \\ kelvya.freitas@ifsertao-pe.edu.br
}

\begin{abstract}
RESUMO: Este estudo propôs analisar as questões de língua espanhola do Exame Nacional do Ensino Médio (ENEM), sob a perspectiva de diagnosticar quais concepções de leituras estão envolvidas neste exame. Portanto, sistematizaram-se e classificaram-se as questões no período de 2010 a 2015, de acordo com as concepções: leitura linguística (leitura das linhas), psicolinguística (leitura entrelinhas) e sociocultural (leitura por detrás das linhas) - (CASSANY, 2006; ABREU, 2011). Nesse sentido, foi possível traçar o perfil do exame, e, identificou-se que, em sua maioria, as questões se atém a concepção psicolinguística. Contudo, o exame apresentou diferentemente de outros vestibulares mostras das três concepções de leitura e isso revela a influência de orientações em compreender o ensino de línguas numa perspectiva de formação cidadã. Deste modo, cabe destacar que esta investigação pautou-se nos últimos direcionamentos sugeridos por documentos governamentais: OCNEM (BRASIL, 2006), LDBEN (BRASIL, 1996) e Diretrizes Curriculares para o Ensino Médio (2013); bem como na fundamentação teórica da abordagem do letramento em sua vertente crítica/sociocultural (BORDÓN, 2006; KLEIMAN,2005; NERY 2003; SCARAMUCCI 2009; LUCKESI 1995).
\end{abstract}

Palavras-chaves: Avaliação, Aprendizagem da língua estrangeira, Vestibular, Formação Cidadã.

\section{Critical Literacies: analyzing the literacy practices in the Spanish Language of students in technical buildings}

\begin{abstract}
This study aimed to analyze the Spanish language issues of the Exame Nacional do Ensino Médio (ENEM),from the perspective of diagnosing which readings conceptions are involved in this examination. Therefore,systematized up and classified to the issues in the period 2010 to 2015, according to the concepts:language reading (reading of the lines), psycholinguistics (lines reading) and sociocultural (read behind the lines) - (CASSANY, 2006; ABREU, 2011). Thus, it was possible to trace the profile of the exam,and it was found that mostly sticks to psycholinguistics design. However, the examination showed unlike other vestibular shows the three conceptions of reading and this reveals the influence of guidance in understanding the teaching of languages in a civic education perspective. Thus, it is worth noting that this research it is guided in recent directions suggested by government documents: OCNEM (BRAZIL,2006), LDBEN (BRAZIL,1996) and Diretrizes Curricalares do Ensino Médio (2013), as well as the theoretical basis of the approach of literacy in their criticism/sociocultural aspects and reading concepts (BORDON,2006;KLEIMAN,2005;NERY 2003; SCARAMUCCI,2009;LUCKESI,1995).
\end{abstract}

Key words: Assessment, Learning Foreign Language, Vestibular, Citizen Training 


\section{Introdução}

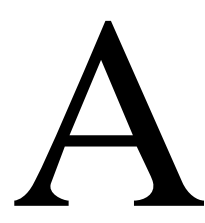

tualmente a sociedade moderna é movida por diversos avanços científicos e tecnológicos, isso faz com que os indivíduos que nela estejam imersos busquem um diferencial, como uma melhor qualificação educacional e/ou profissional. Assim, muitos estudantes buscam ultrapassar a etapa da educação básica, mais precisamente o ensino médio, em busca do seu ingresso no ensino superior.

Contudo, para que haja essa passagem entre os níveis de estudo, é necessário que o aprendiz realize uma seleção (exames de vestibulares em sua maioria). Essa etapa avaliativa exige dos candidatos uma preparação do conteúdo, pois essa se configura como uma prova de conhecimentos adquiridos ao longo dos anos de estudo na educação básica. Diante disso, no ano de 1998 surgiu no sistema educacional brasileiro um novo modelo de prova para os estudantes do nível médio, o chamado Exame Nacional do Ensino (ENEM). Esse exame surgiu com o intuito de possibilitar a vários estudantes a oportunidade de realizar um sonho, já que esse se trata de uma "porta de entrada" para o ingresso ao ensino superior.

Segundo Abreu (2011) e Andriola (2011), o Enem apresentou uma proposta diferente do que se propunha os vestibulares tradicionais de ensino; esse exame trouxe ainda a proposta de "avaliar o desempenho do estudante ao fim da escolaridade básica, visando a aferir o desenvolvimento das competências e habilidades necessárias ao exercício pleno da cidadania" (ANDRIOLA, 2011, p.115). Para Abreu (2011), a mudança nasce em transformar um exame em algo que alie a formação cidadã do sujeito aprendiz:

Entende-se como formação cidadã um conjunto de ações possibilitadas no ambiente educacional: o acesso ao conhecimento; a constituição do sujeito (valores e atitudes); o agir e o posicionar-se no mundo de forma consciente e crítica; o contato com outras formas de interação através da linguagem; a oportunidade de debater e de compreender as desigualdades, relações de poder, na sociedade como um todo; entre outros (ABREU, 2011, p.23).

Dessa forma, ao decorrer dos anos, o Enem passou a ampliar as suas perspectivas na maneira de avaliar os estudantes, uma vez que se objetiva trabalhar com distintas competências e habilidades. Assim, a proposta de avaliação apresentada por esse exame, não consiste em saber o que o aluno foi capaz de decodificar, mas sim o que ele sabe fazer com o conhecimento obtido em anos de estudo. Diante disso, é preciso que o discente tenha ultrapassado a preparação baseada no "decoreba", pois segundo Tiba (2006) uma perspectiva pautada no decoreba baseia-se em "um produto descartável e perecível. Ao ser usada, é descartada. Seu prazo de validade é curto. E se não for usada rapidamente, perece" (p.118). Assim, a aprendizagem baseada no "decoreba" não possibilita a relação dos conhecimentos e para que os estudantes consigam ter um bom desenvolvimento na prova, é preciso compreender os nuances que estão nas entrelinhas dos textos, é necessário que tenham conhecimentos de mundo e consigam compreender a linguagem de forma mais ampla e crítica. Esta característica de entender o que não está dito nas linhas do texto e de atuar de forma crítica na sua interpretação é uma das principais habilidades presente no Exame Nacional do Ensino Médio (ENEM).

Seguindo essa linha de pensamento, esta investigação utilizou para as análises das questões de língua espanhola as perspectivas propostas por Cassany (2006) que propõe uma análise baseada em três concepções de leitura: leitura das linhas (linguística), leitura entre linhas (psicolinguística) e leitura por detrás das linhas (sociocultural). Vale destacar que tal proposta ampliada por Abreu (2011), aborda como as questões de exames se enquadrariam na proposta de Cassany (2006):

Tabela 1: Concepções de leitura.

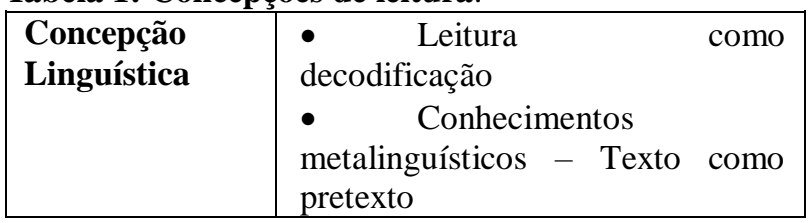




\begin{tabular}{|c|c|}
\hline \multirow[t]{2}{*}{$\begin{array}{l}\text { Concepção } \\
\text { Psicolinguística }\end{array}$} & $\begin{array}{ll}- & \text { Leitura como interação } \\
\text { - } & \text { Conhecimentos }\end{array}$ \\
\hline & $\begin{array}{lll}\text { metalinguísticos } & - & \text { Texto } \\
\text { contextualizado } & & \\
\end{array}$ \\
\hline $\begin{array}{l}\text { Concepção } \\
\text { Sociocultural }\end{array}$ & $\begin{array}{l}\text { Leitura como processamento } \\
\text { sociodiscursivo } \\
\text { • Conhecimentos } \\
\text { Metalinguísticos - Texto } \\
\text { contextualizado } \\
\text { sociohistoricamente } \\
\text { discursivamente }\end{array}$ \\
\hline
\end{tabular}

Fonte: Silva, Abreu (2015).

Dessa forma, o presente artigo é um recorte de dados da pesquisa PIBIC-Jr realizada no Campus Salgueiro (IFSPE), denominada - $A$ Língua Espanhola no ENEM: As entrelinhas nas competências e habilidades exigidas, que sistematizou e classificou as questões do ENEM da prova de língua espanhola, de acordo com as concepções apresentadas por Cassany (2006) e ampliadas por Abreu (2011) em torno das concepções de leitura. Portanto, o presente estudo vem apresentar os dados extraídos desse recorte da pesquisa e assim serão melhor explanadas quando das análises dos dados.

\section{Material e métodos}

Para a presente pesquisa, trabalhou-se com a pesquisa exploratória de cunho interpretativista. Este estudo se traduziu como um estudo diagnóstico, pois se procurou observar, descrever, interpretar e refletir sobre as questões de língua espanhola, que vêm sendo aplicadas no Exame Nacional do Ensino Médio (ENEM), com o objetivo de diagnosticar quais concepções de leituras estão envolvidas nesses exames.

A pesquisa descritiva observa, registra, analisa e correlaciona fatos ou fenômenos (variáveis) sem manipulá-los. Procura descobrir, com a maior precisão possível, a frequência com que o fenômeno ocorre, sua relação e conexão com outros, sua natureza e suas características (CERVO, et.al., 2007, p.61).

É importante ressaltar que se trata também de um recorte longitudinal, já que as análises das questões da língua espanhola foram realizadas com as provas de 2010 a 2015 do ENEM. Tal recorte, justifica-se, pois assim como a perspectiva metodológica proposta por Abreu (2011), que analisou questões de espanhol em vestibulares do Estado do Ceará, faz-se importante vislumbrar como se comporta o exame ao longo dos anos. E isso só seria possível ao delimitar um corte temporal. Dessa forma, é importante mencionar ainda que foi realizado todo o levantamento teórico, com a identificação dos conceitos em torno das concepções de leitura, conhecendo a matriz de referência do ENEM e realizada a devida catalogação de todas as questões de língua espanhola trabalhadas nas provas de 2010 a 2015, com a ideia de se investigar desde a primeira aplicação em 2010 da prova de língua espanhola. Assim, posteriormente, as questões foram classificadas nas concepções de leitura de Cassany (2006): leitura linguística (leitura das linhas), psicolinguística (leitura entrelinhas) e sociocultural (leitura por detrás das linhas).

Ressalta-se que foi construído o instrumento de pesquisa, tratando-se da criação de planilhas com a catalogação das provas de 2010 a 2015 e a devida alimentação dos dados conforme esboça-se na seguinte tabela o modelo usado para a análise das questões (ver tabela 2) ${ }^{1}$.

Tabela 2: Quadro de análise das questões.

\begin{tabular}{|c|c|c|c|c|c|c|c|c|}
\hline 1. & $\begin{array}{c}\text { 2. } \\
\text { Ano }\end{array}$ & $\begin{array}{c}\text { 3. } \\
\text { Situação }\end{array}$ & $\begin{array}{c}\text { 4.Cor } \\
\text { Questão } \\
\text { caderno }\end{array}$ & 5.Texto & $\begin{array}{c}\text { 6. Âmbito de } \\
\text { Circulação }\end{array}$ & $\begin{array}{c}7 . \\
\text { Gabarito }\end{array}$ & $\begin{array}{c}\text { 8. } \\
\text { Habilidade }\end{array}$ & $\begin{array}{c}\text { 9. } \\
\text { Concepção }\end{array}$ \\
\hline
\end{tabular}

Fonte: Silva e Abreu (2016).

\footnotetext{
${ }^{1}$ É importante mencionar que foi feita a catalogação das provas de 2010 a 2015 e a codificação de cada questões,
}

foi realizada segundo a própria numeração da prova do ENEM. 
Deste modo, para se saber qual é a concepção de leitura é mais exigida e trabalhada no ENEM nos últimos cinco anos, foi preciso analisar outros aspectos que são essenciais para a compreensão das concepções de leitura. Assim, de acordo com o modelo de tabela apresentado, na $5^{\mathrm{a}}$ coluna foi realizada a análise dos gêneros textuais que são trabalhados nas questões de língua espanhola na prova do ENEM. É importante ressaltar que a identificaçao do gênero textual pode auxiliar o candidato na resolução das questões, pois esse fornece um suporte para que os aprendizes possam articular e/ou relacionar a conhecimentos prévios de mundo, ou seja, ao reconhecer o gênero discursivo textual, o candidato cria laços de inferências devido ao contato prévio.

Dessa forma, após a identificação do gênero textual, foi realizada a catalogação dos âmbitos de circulação ( $6^{\mathrm{a}}$ coluna das tabela). Dessa forma, a identificação do gênero textual e do âmbito de circulação podem dar suporte para que os aprendizes possam fazer associações de conhecimentos e isso auxiliará na conclusão de uma resposta. Além disso, foram analisadas as habilidades trabalhadas pelo ENEM nos últimos cinco anos ( $8^{\text {a }}$ coluna das tabela). Classificaramse as questões segundo as quatro habilidades (H5, H6, H7, H8) ${ }^{2}$ de acordo com a competência de área 2 apresentada na Matriz de Referência do ENEM.

Com as análises de cada questão de espanhol, a investigação buscou classificá-las segundo as três concepções de leitura e daí diagnosticar o perfil do exame.

\section{Resultados e Discussão}

Atualmente a sociedade moderna requer seres pensantes que conseguem se posicionar e agir de forma autônoma nas diversas situações em sociedade. A criticidade desenvolvida tanto em Língua Materna (LM) como em Língua

\footnotetext{
${ }^{2}$ H5 - Associar vocábulos e expressões de um texto em LEM ao seu tema.

H6 - Utilizar os conhecimentos da LEM e de seus mecanismos como meio de ampliar as possibilidades de acesso a informações, tecnologias e culturas.
}

Estrangeira (LE) pode proporcionar diferentes visões do mundo aos aprendizes, pois esses não ficam à mercê do óbvio, mas buscam compreender o mundo desmistificando estereótipos que circulam na sociedade. Assim, entende-se para este estudo que:

$$
\begin{aligned}
& \text { [...] Ser crítico e fazer uso } \\
& \text { consciente da linguagem é } \\
& \text { valoroso no processo de } \\
& \text { capacitação de um profissional, } \\
& \text { porque promove essa autonomia, } \\
& \text { fazendo com que ele pense, } \\
& \text { reflita e conclua como agir em } \\
& \text { determinada situação, tornando- } \\
& \text { o assim, não meramente mais um } \\
& \text { indivíduo decodificador, mas } \\
& \text { sim um construtor e produtor } \\
& \text { ativo de seu conhecimento } \\
& \text { (ABREU, MORAIS, SILVA, } \\
& \text { 2014, p.7). }
\end{aligned}
$$

Dessa forma, com a análise das questões foi possível conhecer qual o nível de compreensão leitora é mais exigido e trabalhado em língua espanhola como língua estrangeira pelo Exame Nacional do Ensino Médio (ENEM). Já que a prova desse exame se concentra em avaliar a compreensão leitora dos candidatos mais especificamente.

Como já apresentado, este estudo trata-se de um recorte da pesquisa. Deste modo, será apresentado recortes de questões que abordam características das três concepções de leitura: linguística (leitura das linhas), psicolinguística (leitura entrelinhas) e sociocultural (leitura por detrás das linhas) e posteriormente será apresentado a análise em porcentagem destas concepções de leituras.

Para exemplificar melhor essas concepções de leituras, a seguir apresentam-se questões extraídas dos dados destas provas do ENEM.

H7 - Relacionar um texto em LEM, as estruturas linguísticas, sua função e seu uso social.

H8 - Reconhecer a importância da produção cultural em LEM como representação da diversidade cultural e linguística. 
Exemplo 1 - Título: Questão 95 do ano de 2010 (Reaplicado).

\section{Questão 95}

E Camino de la lengua nos lleva hasta el siglo $X$, época en la que aparecen las Glosas Emilianenses en el monasterio de Suso en San Millán (La Rioja). Las Glosas Emilianenses están consideradas como el testimonio escrito más antiguo del castellano. Paso a paso y pueblo a pueblo, el viajero llegará al siglo XV para asistir al nacimiento de la primera Gramática de la Lengua Castellana, la de Nebrija. Más tarde, escritores como Miguel de Cervantes, Calderón de la Barca, Miguel de Unamuno, Santa Teresa de Jesús o el contemporáneo Miguel Delibes irán apareciendo a lo largo del itinerario.

Pero la literatura no es el único atractivo de este viaje que acaba de comenzar.

Nuestra ruta está llena de palacios, conventos, teatros y restaurantes. La riqueza gastronómica de esta región es algo que el viajero debe tener muy en cuenta.

Revista Pumto y Coma. Esparha, n'9, now/6ez, 2007

O "Camino de la lengua", um percurso para turistas na Espanha, conduz o viajante por um roteiro que, além da temática original sobre a lingua e a literatura espanholas, envolve também os aspectos

(A) turísticos e misticos.

B culturais e educacionais.

C históricos e de enriquecimento.

(D) literários e de conflito religioso.

( $)$ arquitetônicos e gastronômicos

Fonte: Prova do ENEM (2010).

A esta primeira amostra, vale destacar que aborda em seu gênero discursivo textual: a notícia, apresentando o contexto histórico da língua espanhola e de igual forma abordando a cultura de um povo, porém, a questão exige apenas a compreensão do último parágrafo utilizando sinonímias para se chegar a resposta correta. Dessa forma, esta questão apresenta característica da Concepção Linguística. Essa concepção orienta $o$ trabalho com a superficialidade do texto, ou seja, a leitura é compreendida como decodificação, os candidatos buscam somente informações pontuais dentro do próprio texto e realizam a extração destes dados para a alternativa correta, às vezes, por meio do uso de sinonímias. Assim, essas questões trabalham com a localização da resposta dentro do próprio texto, em que não é necessário o indivíduo interpretar a questão, segundo a ótica de uma abordagem sociocultural, pois o que se prioriza apenas é localizar informações.

Para ampliar os conceitos em torno das definições das concepções de leitura ora apresentados vale sinalizar trabalhos de Cassany (2006); Abreu (2011); Abreu (2012); Benvenuto e Abreu (2013); Silva e Abreu (2016), por exemplo.

Exemplo 2 - Título: Questão 91 do ano de 2010 (Reaplicado).

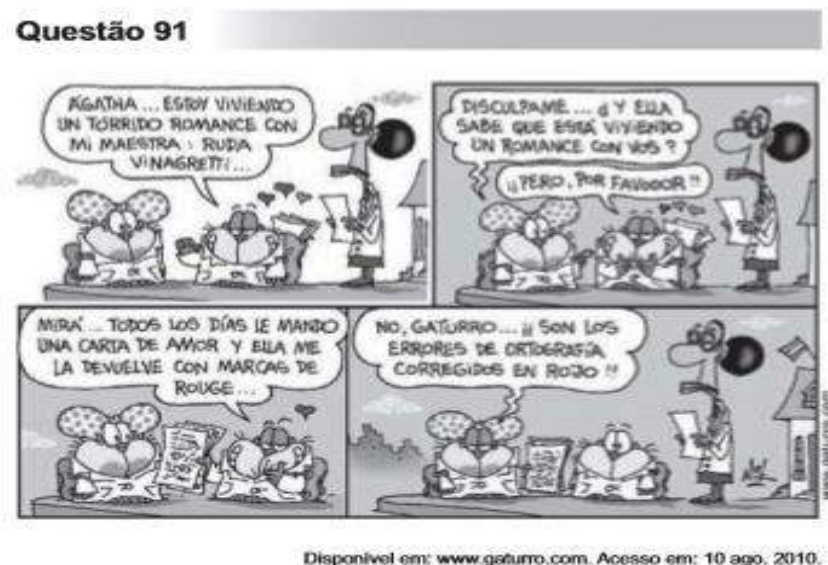

O gênero textual história em quadrinhos pode ser usado com a intenção de provocar humor. $\mathrm{Na}$ tira, o cartunista Nik atinge o climax dessa intençāo quando

A apresenta, já no primeiro quadro, a contradição de humores nas feiçōes da professora e do aluno.

B sugere, com os pontos de exclamação, a entonaçăo incrédula de Gaturro em relaçăo à pergunta de Ágatha.

C compõe um cenário irreal em que uma professora não percebe no texto de um aluno sua verdadeira intenção.

(D) aponta que Ágatha desconstrói a ideia inicial de Gaturro a respeito das reais intençōes da professora.

E congela a imagem de Ágatha, indicando seu desinteresse pela situação vivida por Gaturro.

Fonte: Prova do ENEM (2010).

Esta questão aborda o gênero tira e apresenta características da concepção psicolinguística, utilizando inferências, como: a cor "rojo" e a associação da mesma ao beijo e ao batom. Para resolver a questão o candidato precisava saber a tradução de "rojo", além disso, compreender as intencionalidades usadas pelo autor. Dessa forma, as questões, segundo a Concepção Psicolinguística, trabalham a leitura 
como interação entre o que o texto apresenta com a compreensão do aprendiz, ou seja, nesse caso, para o candidato resolver envolve comparações de informações, compreensão e apreciação global do texto por meio de inferências e conhecimentos prévios linguísticos, textuais e de mundo.

Exemplo 3 - Título: Questão 91 da prova de 2012.

QUESTÃO 91 Obituario*
Lo enterraron en el corazón de un bosque de pinos
y sin embargo
el ataúd de pino fue importado de Ohio;
lo enterraron al borde de una mina de hierro
y sin embargo
los clavos de su ataúd y el hierro de la pala
fueron importados de Pittsburg;
lo enterraron junto al mejor pasto de ovejas del mundo
y sin embargo
las lanas de los festones del ataúd eran de California.
Lo enterraron con un traje de New York,
un par de zapatos de Boston,
una camisa de Cincinatti
y unos calcetines de Chicago.
Guatemala no facilitó nada al funeral,
excepto el cadáver.
* Paráfrasis de un famoso texto norteamericano.
NoGuERAs, L. Las quince mil vidas del caminante. La Habsna: Unes,1977.
O texto de Luis Rogelio Nogueras faz uma crítica
(A) à dependência de produtos estrangeiros por uma nação.
B ao comércio desigual entre Guatemala e Estados Unidos.
C à má qualidade das mercadorias guatemaltecas.
(D às dificuldades para a realização de um funeral.
E à ausência de recursos naturais na Guatemala.

Fonte: Prova do ENEM (2012).

Esta questão que trata do gênero poema, abordando o contexto social e histórico. Para a resolução da questão foi necessário a interpretação e compreensão da poesia, analisando as intencionalidades e críticas feitas pelo autor. Esta questão apresenta características da Concepção Sociocultural, pois trabalha com a criticidade do sujeito, uma leitura por detrás das linhas. A concepção Sociocultural, não fica à mercê de conteúdos memorizados, mas exige dos discentes reflexões e interpretação ao compreender que o discurso não é neutro e é rico em intencionalidades linguístico discursivas.

Assim, segundo as questões analisadas pode-se perceber que a prova de língua espanhola do ENEM contempla as três concepções de leitura (Linguística, Psicolinguística e Sociocultural).

Deste modo, feita toda a codificação das questões, identificação dos gêneros textuais, dos âmbitos de circulação e das habilidades, foi realizada a análise e classificação das trinta e cinco (35 questões) para se diagnosticar quais concepções de leituras estão envolvidas no Exame Nacional do Ensino Médio (ENEM) Conforme Gráfico 1.

Gráfico 1: Concepções de leitura trabalhadas no ENEM.

\section{CONCEPÇÕES DE LEITURA ABORDADAS NO ENEM}

—Linguística Psicolinguística a Sociocultural

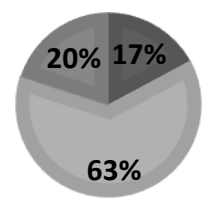

Fonte: Silva e Abreu (2016).

Portanto, segundo os dados apresentados foi possível traçar o perfil do exame, e identificou-se que $63 \%$ dentre as questões investigadas enquadram-se segundo a abordagem psicolinguística, ou seja, questões que trabalham com a leitura em suas entrelinhas, que exigem dos candidatos conhecimentos prévios de mundo, compreensão e apreciação global do texto por meio de inferências, comparação de informações e a formulação de hipóteses.

Deste modo, por meio das análises foi possível compreender que as questões de língua espanhola do ENEM trabalham com a abordagem das três concepções de leitura e como um bom exame, segundo Bordón (2006), traz ao candidato as possibilidades de questões de leitura sob uma ótica de escalas entre fáceis e difíceis. E caso se pense nos efeitos na educação básica, existirá a possibilidade de compreender a relação com o texto de outros modos não minimizando-o a somente a tradução.

\section{Conclusões}


Com a confecção das planilhas e a devida alimentação dos dados, foi possível conhecer a concepção de leitura em língua espanhola adotada no ENEM. Foi possível diagnosticar quais concepções de leituras foram e estão envolvidas nos exames. Conforme esbouçaram-se nos resultados, cerca de $63 \%$, dentre as questões investigadas, abordam a concepção psicolinguística (leitura entrelinhas). Entende-se, portanto, após análise deste estudo que o ENEM exige um nível de compreensão leitora que os indivíduos consigam analisar desde informações pontuais, termos de sinonímias até as intencionalidades do discurso nas entrelinhas dos textos ou por detrás do texto, fazendo associações de conhecimentos dentro e fora do texto ao formular hipóteses.

Deste modo, nota-se que se comparado a outros estudos, tais como apresentados por Abreu (2011), o Exame Nacional do Ensino Médio rompe com a concepção tradicionalista de provas de línguas visando apenas a localização de informações pontuais (concepção linguística) ou até mesmo em questão de sinonímias (concepção linguística), quando muito traziam questões de conhecimentos metalinguísticos dissociados ao texto proposto. Verifica-se que apesar de se sobressair a concepção psicolinguística, observa-se que o exame mescla características das três concepções de leituras - ver as porcentagens no gráfico 1, isso sinaliza que o exame encontra-se atento ao público que o faz, bem como do público esperado para futuras instituições superiores. Ou seja, observa-se que além de trabalhar a concepção linguística o exame propõe questões que dão margem a uma análise mais crítica e aprofundada dos textos, por meio da concepção sociocultural e é neste ponto que o exame ao contemplar as três concepções conseguirá produzir impactos na educação básica, pois irá fomentar o debate de textos para a formação cidadã, assim como proposto por documentos governamentais, tais como a própria Lei de Diretrizes e Bases da Educação Nacional, $n^{\circ} 9.394 / 96$, e as Orientações Curriculares do Ensino Médio - (OCNEM, BRASI, 2006).

\section{Agradecimentos}

As pesquisadoras desta investigação agradecem o apoio do Instituto Federal de Educação, Ciência e Tecnologia do Sertão Pernambucano ao financiar e proporcionar a vivência acadêmica e investigativa por meio da pesquisa do Programa de Iniciação de Bolsa Científica Jr. (PIBIC-JR.) realizada no Campus Salgueiro (IFSPE) e ao Grupo de Estudos e Pesquisas em Práticas Educacionais Tecnológicas (GEPET), pelo apoio para o desenvolvimento da pesquisa: $A$ Língua Espanhola no ENEM: As entrelinhas nas competências e habilidades exigidas.

\section{Referências}

ABREU, K.F. Concepções de leitura e de texto subjacentes às provas de vestibular: constatações e implicações para o ensino da língua espanhola. Dissertação (Mestrado em Linguística). Universidade Federal do Ceará. Fortaleza, 2011.

Concepções de leitura no ensino de espanhol como língua estrangeira: em busca de uma abordagem sociocultural. In: BAPTISTA, L.M.T.R.(Org.). Múltiplas Perspectivas, Múltiplos Sentidos: o ensino e a aprendizagem do espanhol em foco. 1ed.Brasília: Editora Kiron, 2012, v. , p. 139-155.

ABREU, K. F; MORAIS, H. T. F; SILVA, M. R. $\mathrm{V}$. Eventos de letramento (s) em português e em

espanhol: a abordagem crítica na área de edificações. In: Anais do I Colóquio de Análise do Discurso (CNAD), 2014, Pau dos Ferros: UERN: 2014.

ANDRIOLA, W.B. Doze motivos favoráveis à adoção do Exame Nacional do Ensino Médio (ENEM) pelas Instituições Federais de Ensino Superior (IFES). Ensaio: aval. pol. públ. Educ., Rio de Janeiro, v. 19, n. 70, p. 107-126, jan./mar. 2011.

BENVENUTO, E. V. ; ABREU, K. F. . Letramento(s): em busca do exercício da plena cidadania. IN: VIII Congresso Norte e Nordeste de Pesquisa e Inovação - Connepi, 2014, 
Salvador. Anais do VIII Connepi. Salvador: IFBahia e IFBahiano, 2013.

BRASIL. Orientações Curriculares para o Ensino Médio: Linguagens, Códigos e suas Tecnologias. Brasília, Secretaria de Educação Básica, 2006. Disponível em: http://portal.mec.gov.br/seb/arquivos/pdf/book_ volume_01_internet.pdf . Acessado em:02/02/2015.

CASSANY, D. Tras las líneas. Sobre la lectura contemporánea. Barcelona: Editorial Anagrama, 2006.

CERVO, A.L. Metodologia científica. $6^{\mathrm{a} e d . ~ S a ̃ o ~}$ Paulo: Pearson Prentice Hall, 2007.

KLEIMAN, Â. Preciso “ensinar" o letramento? Não basta ensinar a ler e a escrever? São Paulo: Produção Editorial, 2005.

LUCKESI, C. C. Avaliação da aprendizagem Escolar. 10 ed. São Paulo: Cortez, 1995.

SCARAMUCCI, M.V.R. Avaliação da leitura em inglês como língua estrangeira e validade de constructo. In: Revista Calidoscópio. Vol.7, n.1, p. 30-48, jan/abr 2009.

SILVA, M. R. V. ; ABREU, K. F. . Avaliação e letramento(s): construindo pontes possíveis. In: OLIVEIRA, F.K.; ABREU, K.F.. (Org.). Métodos e pesquisas em educação. 1ed.Brasília: Kiron, 2016, v. 1, p. 115-137.

TIBA, I. Ensinar aprendendo: Novos paradigmas na educação. 18 ed. São Paulo: Integrare Editora, 2006. 